\title{
Heterosis serta Keragaan Karakter Vegetatif Tomat (Lycopersicon esculentum Mill.) Hasil Persilangan Half Diallel
}

\section{Heterosis and Performance of Vegetative Traits in Tomato (Lycopersicon esculentum Mill.) from Half Diallel Crossing}

\author{
Estriana Riti ${ }^{1}$, Muhamad Syukur ${ }^{1 *}$ \\ ${ }^{1}$ Departemen Agronomi dan Hortikultura, Fakultas Pertanian, Institut Pertanian Bogor (Bogor Agricultural University) \\ Jl Meranti, Kampus IPB Darmaga, Bogor 16680, Indonesia.
}

Diterima 27 Oktober 2017/Disetujui 4 Januari 2018

\begin{abstract}
Tomato is valuable horticultural comodity in Indonesia. The aims of this research was to study heterosis and performace of vegetative traits from half diallel tomato crossing. This research conducted at Leuwikopo Experimenal Field, Bogor Agricultural University during April sampai Juli 2013. Results showed that the hybrids which had the best heterosis was not always followed by the best heterobeltiosis. Genotypes T73xT78 and T13xT64 had the best heterosis and heterobeltiosis in stem diameter and leaf width respectively. Genotype T13 had the best performance for plant high and had significant difference with check varieties.
\end{abstract}

Key words: genotypes, heterobeltiosis, horticulture, hybrids, varieties

\section{ABSTRAK}

Tomat merupakan komoditas hortikultura yang banyak dibudidayakan di Indonesia. Penelitian ini bertujuan untuk mempelajari heterosis dan keragaan karakter vegetatif hasil persilangan half diallel tomat. Percobaan dilaksanakan di Kebun Percobaan Leuwikopo, Institut Pertanian Bogor pada bulan April - Juli 2013. Hasil penelitian menunjukkan nilai heterosis tinggi tidak selalu diikuti oleh nilai heterobeltiosis tinggi. Genotipe yang memiliki keunggulan heterosis dan heterobeltiosis adalah T73xT78 dan T13xT64 masing-masing pada karakter diameter batang dan lebar daun. Genotipe T13 memiliki keragaan karakter tinggi tanaman lebih baik dari ketiga pembanding.

Kata kunci : genotipe, heterobeltiosis, hibrida, hortikultura, varietas

\section{PENDAHULUAN}

Tomat (Lycopersicon esculentum Mill.) merupakan komoditas hortikultura yang bernilai ekonomis tinggi. Kandungan nutrisi pada tomat sebagai salah satu sumber mineral, vitamin $\mathrm{A}$ dan $\mathrm{C}$ membuat tomat banyak dicari. Produktivitas tomat Indonesia tahun 2007-2010 mencapai nilai 15.23 ton per hektar (Kementan, 2013), sedangkan potensi produktivitas tomat dapat mencapai $>50$ ton per hektar (Soedomo, 2012).

Varietas tomat unggul terus menerus diperlukan untuk memenuhi berbagai keragaman agroekologi yang cukup luas, termasuk berkurangnya dataran tinggi yang cocok untuk pertumbuhan tomat Purwati (2007). Tanaman tomat yang ditanam tidak pada lingkungan yang sesuai akan mengalami cekaman (Haghighi et al., 2014). Pengembangan varietas

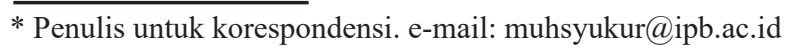

tomat untuk penanaman di dataran rendah memerlukan banyak studi lanjut. Persilangan diallel merupakan metode untuk meningkatkan keragaman genetik tanaman yang didesain mewakili populasi di alam. Keragaman genetik yang dihasilkan dari persilangan diallel tersebut digunakan sebagai sumber perakitan varietas baru. Persilangan diallel dilakukan dengan mengombinasikan semua tetua yang ada. Persilangan half diallel merupakan persilangan yang menggunakan setengah kombinasi persilangan diallel. Penggunaan metode persilangan diallel pada tomat telah dilakukan oleh De Souza et al. (2012).

Heterosis adalah keunggulan hibrida (hybrid vigour) atau hasil persilangan (F1) yang melebihi nilai kisaran ratarata kedua tetuanya (Syukur et al., 2012; Patwary et al., 2013). Heterosis dapat terjadi karena adanya akumulasi gen dominan atau gen over-dominan. Keunggulan turunan hasil silang diallel dapat dinilai dari besarnya nilai heterosis, heterobeltiosis, daya gabung umum dan daya gabung khusus. Nilai heterosis pada tomat dapat ditemukan pada jumlah buah, panjang buah, bobot buah dan produksi per tanaman 
(Gul et al., 2010). Heterosis adalah penampilan hibrida dibandingkan dengan rata-rata kedua tetuanya. Heterosis dengan tetua terbaik disebut dengan heterobeltiosis. Heterosis dapat disebabkan dari adanya dominasi penuh atau sebagian, overdominan, epistasis, maupun kombinasi dari ketiganya. Pengamatan heterosis pada tanaman tomat telah dilakukan oleh Shende et al. (2012), Savita dan Singh (2015) serta Tamta dan Singh (2017). Penelitian ini bertujuan untuk menduga nilai heterosis karakter vegetatif serta mengevaluasi keragaan karakter vegetataif tomat hasil persilangan half diallel di dataran rendah.

\section{BAHAN DAN METODE}

\section{Materi Genetik}

Material genetik yang digunakan pada penelitian ini adalah tanaman tomat sebanyak 15 genotipe $\mathrm{F} 1$ hasil silang half dialel, 6 genotipe tetua, dan 3 varietas komersial sebagai pembanding. Genotipe tetua yang digunakan adalah T1, T3, T13, T64, T73 dan T78. Hibrida yang dipakai adalah T1xT3, T1xT13, T1xT64, T1xT73, T1xT78, T3xT13, T3xT64, T3xT73, Т3хT73, Т3хT78, T13xT64, T13xT73, Т13xT78, T64xT73, T64xT78, T73xT78 (Tabel 1). Pembanding yang digunakan adalah tomat hibrida varietas Permata F1, Fortuna 23 dan New Mutiara.

\section{Rancangan Percobaan}

Rancangan lingkungan yang digunakan adalah Rancangan Kelompok Lengkap Teracak (RKLT) dengan satu faktor, yaitu genotipe dengan tiga ulangan sebagai kelompok. Pengelompokan dilakukan berdasarkan adanya naungan pada lokasi penanaman. Percobaan dilakukan sebanyak 3 (tiga) ulangan. Tiap ulangan terdiri dari 24 genotipe sehingga terdapat 72 satuan percobaan. Tiap satuan percobaan terdiri dari 20 tanaman, sehingga total terdapat 1440 tanaman. Pengaruh genotipe terhadap komponen pengamatan diuji $\mathrm{F}$ pada taraf nyata $5 \%$ dan $1 \%$ dilanjutkan dengan uji DMRT pada taraf 5\%.

Nilai heterosis pada penampilan hibrida dan heterobeltiosis dihitung menggunakan perbandingan hibrida dan tetuanya. Heterosis $(\mathrm{H})$ dan heterobeltiosis $(\mathrm{Hb})$ dihitung dengan rumus berturut-turut $\mathrm{H}=(\mathrm{F} 1-\mathrm{MP}) / \mathrm{MP}$ x $100 \%$ dan $\mathrm{Hb}=(\mathrm{F} 1-\mathrm{Pi}) / \mathrm{Pi}$ x $100 \%$, dengan F1adalah hibrida, MP adalah rerata nilai kedua tetua dan Pi nilai tetua terbaik.

\section{Pelaksanaan}

Percobaan dilaksanakan pada bulan April - Juli 2013 di Kebun Percobaan Leuwikopo, Institut Pertanian Bogor dengan ketinggian lahan 250 mdpl. Pengolahan lahan dan pembuatan bedengan dilakukan bersamaan saat kegiatan penyemaian. Penanaman dilakukan setelah bibit tomat berumur 4 minggu setelah semai atau minimal sudah memiliki empat helai daun. Petak bedengan dibuat dengan ukuran $1 \mathrm{~m}$ x $5 \mathrm{~m}$ untuk setiap perlakuan dengan jarak antar bedengan $0.5 \mathrm{~m}$. Setiap bedengan diberi pupuk kandang sebanyak $20 \mathrm{~kg}$ dan kapur $0.5 \mathrm{~kg}$. Setelah pemberian pupuk kandang selama 2 minggu, bedengan ditutup dengan mulsa plastik hitam perak (MPHP) dan dibuat lubang tanaman menggunakan alat 'cemplong' dengan jarak $0.5 \mathrm{~m}$ x $0.5 \mathrm{~m}$.

Penyemaian dilakukan di Laboratorium Pemuliaaan Tanaman. Fakultas Pertanian Institut Pertanian Bogor. Penyemaian dilakukan menggunakan tray semai berukuran $6 \times 12$ sehingga terdapat 72 lubang. Setiap genotipe disemai dalam satu tray sehingga total tray yang digunakan untuk menyemai berjumlah 24 tray. Media persemaian merupakan campuran antara pupuk kompos dan media semai dengan perbandingan 1:1. Media dimasukkan dalam tray semai dan dipadatkan. Benih dimasukkan dalam lubang tray sebanyak 1 butir per lubang. Penyulaman persemaian dilakukan satu minggu setelah semai. Penyiraman persemaian dilakukan setiap pagi dan sore selama 4 minggu.

Penanaman dilakukan setelah bibit berumur 4 minggu atau setelah bibit memiliki sedikitnya 4 helai daun. Penanaman dilakukan pada sore hari dengan jumlah tanaman satu tanaman per lubang tanam. Bibit ditanam dalam cemplongan dan diberi ajir. Bibit diikat ke ajir untuk menghindari rebah. Penyulaman bibit dilakukan satu minggu setelah tanam. Bibit ditanam dengan jarak tanam $0.5 \mathrm{~m}$ x 0.5 m dengan jumlah 1 (satu) tanaman per lubang.

Pemeliharaan dilakukan selama masa penanaman. Pemeliharaan tanaman meliputi penyiraman, pemupukan, pengajiran, pengikatan tanaman, pemberian pestisida, pewiwilan tunas air dan penyiangan gulma. Penyiraman dilakukan pada pagi dan sore hari jika tidak terjadi hujan

Tabel 1. Material genetik persilangan half diallel

\begin{tabular}{|c|c|c|c|c|c|c|}
\hline $9 / 0$ & $\mathrm{~T} 1$ & $\mathrm{~T} 3$ & $\mathrm{~T} 13$ & T64 & $\mathrm{T} 73$ & $\mathrm{~T} 78$ \\
\hline $\mathrm{T} 1$ & $\mathrm{~T} 1$ & $\mathrm{~T} 1 \times \mathrm{T} 3$ & $\mathrm{~T} 1 \times \mathrm{T} 13$ & T1 x T64 & $\mathrm{T} 1 \times \mathrm{T} 73$ & $\mathrm{~T} 1 \times \mathrm{T} 78$ \\
\hline $\mathrm{T} 3$ & - & $\mathrm{T} 3$ & $\mathrm{~T} 3 \times \mathrm{T} 13$ & T3 x T64 & $\mathrm{T} 3 \times \mathrm{T} 73$ & $\mathrm{~T} 3 \times \mathrm{T} 78$ \\
\hline $\mathrm{T} 13$ & - & - & $\mathrm{T} 13$ & $\mathrm{~T} 13 \times \mathrm{T} 64$ & $\mathrm{~T} 13 \times \mathrm{T} 73$ & $\mathrm{~T} 3 \times \mathrm{T} 78$ \\
\hline T64 & - & - & - & T64 & $\mathrm{T} 64 \times \mathrm{T} 73$ & $\mathrm{~T} 64 \times \mathrm{T} 78$ \\
\hline $\mathrm{T} 73$ & - & - & - & - & $\mathrm{T} 73$ & $\mathrm{~T} 73 \times \mathrm{T} 78$ \\
\hline $\mathrm{T} 78$ & - & - & - & - & - & $\mathrm{T} 78$ \\
\hline
\end{tabular}


sebanyak 20 liter per bedeng atau sampai keadaan tanah menjadi lembab. Pemupukan dilakukan setiap satu minggu sekali setelah satu minggu setelah tanam (1 MST) dengan menggunakan pupuk NPK Mutiara dengan konsentrasi 10 $\mathrm{g} \mathrm{L}^{-1}$ sebanyak $250 \mathrm{ml}$ per tanaman. Pengikatan tanaman dilakukan saat tajuk tanaman sudah menjauhi ajir. Penyemprotan pestisida dilakukan 2 minggu sekali dengan menggunakan fungisida Dithane M-45 atau antracol $2 \mathrm{~g} \mathrm{~L}^{-1}$, insektisida Curacron dengan konsentrasi $2 \mathrm{ml} \mathrm{L}^{-1}$. Pewiwilan tunas air dilakukan agar tanaman dapat tumbuh optimal. Pengendalian gulma dilakukan secara manual.

Kegiatan pemanenan dilakukan pada saat buah tomat telah mencapai tingkat kematangan $75 \%$. Pemanenan dilakukan setiap 5 hari sekali selama 8 kali panen. Cara melakukan pemanenan yaitu dengan melepas buah tomat dari tangkai buah satu demi satu selanjutnya dimasukkan ke dalam plastik dan diberi label meliputi nomor tanaman, genotipe dan tanggal panen.

Pengamatan dilakukan pada 10 tanaman contoh. Tanaman contoh dipilih secara acak selain tanaman pinggir pada 20 tanaman dalam bedeng. Pengamatan yang dilakukan meliputi tinggi tanaman, diameter batang, panjang daun, lebar daun dan umur berbunga.

\section{HASIL DAN PEMBAHASAN}

\section{Heterosis dan Heterobeltiosis}

Karakter tinggi tanaman, diameter batang, lebar daun, dan panjang daun merupakan karakter yang diharapkan memiliki nilai heterosis positif. Dugaan rentang nilai heterosis pada karakter tinggi tanaman adalah -20.42-9.20\%, diameter batang adalah $-18.20-2.59 \%$, panjang daun adalah $-13.86-18.94 \%$ dan lebar daun adalah $-11.97-37.59 \%$. Nilai heterosis terbaik untuk karakter tinggi tanaman, diameter batang, panjang daun, dan lebar daun berturut-turut dimiliki oleh persilangan T13 x T78, T73 x T78, T13 x T64, dan T13 x T64 (Tabel 2).

Nilai heterosis tinggi tanaman lebih rendah dari penelitian Hannan et al. (2007) yaitu sebesar 65.35\%. Tinggi tanaman diharapkan memiliki nilai positif karena semakin tinggi tanaman maka diharapkan semakin banyak terbentuk bunga dan buah pada tiap bukunya. Penelitian Hannan et al. (2007) menunjukkan tinggi tanaman berkorelasi positif dengan jumlah buah per tanaman. Karakter diameter batang memiliki peran penting untuk menjaga ketegaran tanaman. Hal ini dikarenakan tanaman yang memiliki diameter batang besar akan mampu menopang tanaman dengan baik. Karakter lebar dan panjang daun berkorelasi dengan kemampuan menyerap sinar matahari dan proses fotosintesis. Ukuran daun yang besar akan meningkatkan efektifitas fotosintesis sehingga memungkinkan mendapatkan hasil produksi tinggi.

Karakter umur berbunga merupakan karakter yang diharapkan memiliki nilai heterosis negatif. Umur berbunga hibrida tomat memiliki nilai duga heterosis pada kisaran $-7.93-8.33 \%$. Terdapat enam hibrida yang memiliki nilai heterosis negatif. Nilai heterosis terbaik pada persilangan T3xT64. Nilai heterosis negatif menunjukkan bahwa hibrida tomat lebih genjah dari rata-rata tetua. Patwary et al. (2013) menemukan bahwa nilai heterosis umur berbunga tomat dapat mencapai $27.65 \%$. Heterosis pada tomat disebabkan oleh gen single flower truss ( $s f t$ ) yang mengkode hormon pembungaan florigen. Gen tersebut dapat menyebabkan

Tabel 2. Nilai heterosis karakter vegetatif tomat (\%)

\begin{tabular}{lccccc}
\hline \multicolumn{1}{c}{ Genotipe } & Tinggi tanaman & Diameter batang & Panjang daun & Lebar daun & Umur berbunga \\
\hline T1 x T3 & -7.03 & -3.07 & -5.43 & -0.41 & 0.52 \\
T1 x T13 & -20.42 & -9.57 & -7.81 & 1.49 & -2.02 \\
T1 x T64 & -3.48 & -6.11 & -5.43 & -0.61 & -4.95 \\
T1 x T73 & 6.14 & -0.76 & -8.41 & -5.48 & 1.52 \\
T1 x T78 & -1.29 & -10.24 & -13.86 & -7.62 & -3.06 \\
T3 x T13 & -9.81 & -12.9 & -1.65 & -8.47 & 3.78 \\
T3 x T64 & -10.02 & -14.26 & 5.55 & 8.29 & -7.93 \\
T3 x T73 & 7.31 & 1.23 & -6.07 & -11.97 & 6.52 \\
T3 x T78 & -17.06 & -5.1 & -2.15 & 0.43 & 2.73 \\
T13 x T64 & -3.8 & -5.8 & 18.94 & 37.59 & -5.05 \\
T13 x T73 & -4.13 & -15.21 & -0.19 & 2.43 & 7.77 \\
T13 x T78 & 9.2 & -5.07 & -5.87 & -4.19 & 8.33 \\
T64 x T73 & -10.41 & -18.2 & -6.76 & -2.55 & 3.55 \\
T64 x T78 & -5.28 & -12.62 & -5.63 & -2.87 & 5.1 \\
T73 x T78 & -0.53 & 2.59 & 14.88 & 11.12 & -4.71 \\
\hline
\end{tabular}


keterlambatan pembungaan dengan jumlah bunga serta buah sedikit, namun pada keadaan heterozigot mampu menghasilkan peningkatan hasil yang sangat tinggi (Jiang et al., 2013).

Karakter tinggi tanaman, diameter batang, lebar daun, dan panjang daun merupakan karakter yang diharapkan memiliki nilai heterobeltiosis positif. Dugaan rentang nilai heterobeltiosis pada karakter tinggi tanaman adalah -34.78$1.28 \%$, diameter batang adalah $-23.59-2.35 \%$, panjang daun adalah -24.00-7.61\% dan lebar daun adalah -27.77-22.96\% (Tabel 3). Nilai heterobeltiosis terbaik untuk karakter tinggi tanaman, diameter batang, panjang daun dan lebar daun berturut-turut dimiliki oleh persilangan T3xT73, T73xT78, T64xT73, dan T13xT64. Nilai heterobeltiosis umur berbunga diharapkan bernilai negatif. Dugaan nilai heterobeltiosis umur berbunga pada kisaran -4.95-11.36\%. Persilangan yang memiliki nilai heterobeltiosis terbaik adalah T1xT64, namun tidak berbeda nyata dengan tetua terbaiknya. Keunggulan nilai heterobeltiosis pada tiap karakter yang dimiliki oleh kombinasi persilangan berbeda ini sesuai dengan penelitian Herison et al. (2017).

\section{Keragaan Tanaman}

Keragaan tanaman merupakan tampilan fenotipe sebagai perwujudan genotipe dan respon terhadap kondisi lingkungan tertentu. Tomat yang ditanam pada dataran rendah dengan suhu relatif lebih panas dari dataran tinggi dapat mengalami cekaman panas yang menyebabkan hilangnya air secara cepat pada permukaan tanaman. Kehilangan air tersebut dapat menyebabkan dehidrasi pada jaringan dan organ tanaman sehingga menghambat pertumbuhan (Shaheen et al., 2015). Keragaan tanaman dikendalikan oleh banyak gen minor dan diwariskan secara aditif (Arif, 2010).

Rekapitulasi sidik ragam (Tabel 4) menunjukkan bahwa genotipe berpengaruh nyata pada karakter tinggi tanaman, diameter batang, panjang daun, lebar daun dan umur berbunga. Hasil uji DMRT menunjukkan perbedaan nilai pada seluruh karakter yang diamati pada semua genotipe (Tabel 5). Keragaman yang tinggi pada tetua menyebabkan keragaman F1 juga tinggi. Rekombinasi gen terjadi pada generasi F1. Perbedaan keragaan tanaman dapat terjadi akibat perbedaan kombinasi gen.

Keragaan tinggi tanaman terbaik dimiliki oleh T13 dan berbeda nyata dengan semua varietas pembanding. Rentang nilai tinggi tanaman adalah $71.58-112.03 \mathrm{~cm}$, nilai ini lebih tinggi dari hasil penelitian Sumiasih et al. (2014) yaitu sebesar $54.00-102.30 \mathrm{~cm}$. Keragaan diameter batang terbaik juga dimiliki oleh T13 namun tidak berbeda nyata dengan pembanding varietas Permata dan New Mutiara. Tanaman yang memiliki batang berdiameter besar akan lebih kuat dalam menahan bobot buah yang dihasilkan.

Keragaan panjang daun dan lebar daun terbaik dimiliki oleh T78, dan T13xT64 namun semua tidak berbeda nyata dengan pembanding varietas Permata dan New Mutiara. Tanaman yang memiliki daun berukuran panjang dan lebar diharapkan dapat menyerap sinar matahari lebih banyak sehingga proses fotosintesis lebih optimal. Proses perkembangan morfologi daun diatur oleh hormon tanaman, regulator transkripsi dan perlengkapan mekanis pada jaringan tanaman (Bar dan Ori, 2014). Karakter umur berbunga paling

Tabel 3. Nilai heterobeltiosis karakter vegetatif tomat (\%)

\begin{tabular}{lccccc}
\hline \multicolumn{1}{c}{ Genotipe } & Tinggi tanaman & Diameter batang & Panjang daun & Lebar daun & Umur berbunga \\
\hline T1 x T3 & -15 & -8.45 & -0.97 & -3.26 & 7.95 \\
T1 x T13 & $-34.78^{* *}$ & -17.6 & -19.67 & -12.22 & 0 \\
T1 x T64 & -8.65 & -8.7 & -9.33 & -4.24 & -4.95 \\
T1 x T73 & -11.25 & -1.97 & $-24.00^{*}$ & -24.17 & 4.16 \\
T1 x T78 & -4.31 & $-11.54^{*}$ & -14.05 & -7.83 & 0 \\
T3 x T13 & $-16.87^{*}$ & -16.16 & -10.84 & -18.8 & 9.09 \\
T3 x T64 & -16.84 & $-16.80^{*}$ & 5.33 & 7.38 & -1.13 \\
T3 x T73 & 1.28 & -5.49 & -19.13 & -27.77 & 11.36 \\
T3 x T78 & $-25.06^{*}$ & -11.59 & -6.57 & -2.66 & 6.81 \\
T13 x T64 & $-17.47^{*}$ & -11.91 & 7.61 & 22.96 & -3.09 \\
T13 x T73 & -6.51 & $-23.59^{*}$ & -5.79 & -6.38 & 8.33 \\
T13 x T78 & -8.23 & -14.63 & $-18.13 *$ & -17.28 & 9.47 \\
T64 x T73 & $-21.48^{* *}$ & -21.4 & $-19.87 *$ & -19.51 & 6.25 \\
T64 x T78 & -7.59 & -16.23 & -9.71 & -6.61 & 8.42 \\
T73 x T78 & $-14.64^{*}$ & 2.35 & -4.84 & -11.01 & -4.21 \\
\hline
\end{tabular}

Keterangan: $\operatorname{tn},{ }^{*}, * *$ berturut-turut hasil uji $\mathrm{F}$ tidak nyata pada taraf $5 \%$, nyata pada taraf $5 \%$, nyata pada taraf $1 \%$ 
cepat dimiliki oleh genotipe T3xT64 (29.00 HST) namun tidak berbeda nyata dengan varietas pembanding New Mutiara. Umur berbunga tercepat ini lebih lambat dari hasil penelitian Sumiasih et al. (2014) yaitu sebesar 16.67 HST. Perbedaan umur panen ini diduga disebabkan perbedaan iklim dan jenis genotipe yang digunakan. Keragaan karakter

Tabel 4. Rekapitulasi sidik ragam terhadap 14 karakter dari 6 tetua, 15 hibrida silang half diallel dan 3 varietas komersial

\begin{tabular}{clcccccc}
\hline \multirow{2}{*}{ No } & \multirow{2}{*}{ Karakter } & \multicolumn{2}{c}{ Kuadrat tengah } & \multirow{2}{*}{ F hitung } & & Pr $>$ F & KK $(\%)$ \\
\cline { 3 - 5 } & & Genotipe & Galat & & & \\
\hline 1 & Tinggi tanaman & 466.38 & 72.19 & & $6.46^{* *}$ & $<.0001$ & 9.78 \\
2 & Diameter batang & 3.27 & 1.5 & $2.18^{*}$ & 0.011 & 10.62 \\
3 & Panjang daun & 42.5 & 10.78 & $3.94^{* *}$ & $<.0001$ & 11.02 \\
4 & Lebar daun & 31.67 & 8.08 & $3.92^{* *}$ & $<.0001$ & 14.11 \\
5 & Umur berbunga & 7.18 & 2.66 & $2.70^{* *}$ & 0.002 & 5.04 \\
\hline
\end{tabular}

Keterangan: $\mathrm{KK}=$ koefisien keragaman, $\mathrm{tn},{ }^{*}, * *=$ berturut-turut hasil uji $\mathrm{F}$ tidak nyata pada taraf $5 \%$, nyata pada taraf $5 \%$, nyata pada $\operatorname{taraf} 1 \%$

Tabel 5. Keragaan karakter vegetatif tomat

\begin{tabular}{|c|c|c|c|c|c|}
\hline Genotipe & $\begin{array}{l}\text { Tinggi tanaman } \\
(\mathrm{cm})\end{array}$ & $\begin{array}{c}\text { Diameter batang } \\
(\mathrm{mm})\end{array}$ & $\begin{array}{c}\text { Panjang daun } \\
(\mathrm{cm})\end{array}$ & $\begin{array}{l}\text { Lebar daun } \\
(\mathrm{cm})\end{array}$ & $\begin{array}{c}\text { Umur berbunga } \\
\text { (HST) }\end{array}$ \\
\hline $\mathrm{T} 1$ & $71.58 \mathrm{~h}$ & $11.62 b-e$ & $34.06 \mathrm{ab}$ & $22.64 a-d$ & $33.67 \mathrm{ab}$ \\
\hline $\mathrm{T} 1 \times \mathrm{T} 3$ & $73.43 \mathrm{gh}$ & $11.97 \mathrm{a}-\mathrm{d}$ & $30.82 a-e$ & 21.89a-e & 31.67a-e \\
\hline $\mathrm{T} 1 \times \mathrm{T} 13$ & $73.06 \mathrm{gh}$ & $11.65 \mathrm{~b}-\mathrm{e}$ & $27.36 \mathrm{c}-\mathrm{g}$ & $19.87 \mathrm{c}-\mathrm{g}$ & $32.33 a-d$ \\
\hline $\mathrm{T} 1 \times \mathrm{T} 64$ & $73.23 \mathrm{gh}$ & $11.23 \mathrm{~b}-\mathrm{e}$ & $30.88 \mathrm{a}-\mathrm{e}$ & 21.68a-e & $32 \mathrm{a}-\mathrm{e}$ \\
\hline $\mathrm{T} 1 \times \mathrm{T} 73$ & $94.49 \mathrm{~b}-\mathrm{e}$ & $11.39 \mathrm{~b}-\mathrm{e}$ & $25.88 \mathrm{~d}-\mathrm{g}$ & $17.16 \mathrm{~d}-\mathrm{h}$ & $33.33 \mathrm{abc}$ \\
\hline $\mathrm{T} 1 \times \mathrm{T} 78$ & $72.97 \mathrm{gh}$ & $10.28 \mathrm{cde}$ & $29.4 b-f$ & 20.96a-f & $31.67 \mathrm{a}-\mathrm{e}$ \\
\hline $\mathrm{T} 3$ & $86.39 \mathrm{e}-\mathrm{h}$ & $13.08 \mathrm{ab}$ & $31.12 \mathrm{a}-\mathrm{e}$ & $21.34 \mathrm{a}-\mathrm{e}$ & 29.33de \\
\hline $\mathrm{T} 3 \times \mathrm{T} 13$ & $93.13 \mathrm{~b}-\mathrm{e}$ & $11.85 \mathrm{a}-\mathrm{d}$ & $27.75 \mathrm{~b}-\mathrm{g}$ & $17.33 \mathrm{c}-\mathrm{h}$ & $32 \mathrm{a}-\mathrm{e}$ \\
\hline T3 x T64 & $78.58 \mathrm{e}-\mathrm{h}$ & $10.88 b-\mathrm{e}$ & $32.92 \mathrm{abc}$ & $22.92 \mathrm{abc}$ & $29 \mathrm{e}$ \\
\hline $\mathrm{T} 3 \times \mathrm{T} 73$ & $107.83 \mathrm{ab}$ & $12.36 \mathrm{abc}$ & $25.17 \mathrm{efg}$ & $15.41 \mathrm{gh}$ & $32.67 \mathrm{abc}$ \\
\hline T3 x T78 & $70.81 \mathrm{~h}$ & $11.56 \mathrm{~b}-\mathrm{e}$ & $31.96 a-d$ & $22.13 \mathrm{a}-\mathrm{e}$ & $31.33 \mathrm{cde}$ \\
\hline T13 & $112.03 \mathrm{a}$ & $14.14 \mathrm{a}$ & $25.3 \mathrm{efg}$ & $16.52 \mathrm{e}-\mathrm{h}$ & $32.33 \mathrm{a}-\mathrm{d}$ \\
\hline T13 x T64 & $92.45 b-f$ & $12.45 \mathrm{abc}$ & $33.63 \mathrm{abc}$ & $25.8 \mathrm{ab}$ & $31.33 \mathrm{~b}-\mathrm{e}$ \\
\hline $\mathrm{T} 13 \times \mathrm{T} 73$ & $104.74 a-d$ & $10.8 b-e$ & $23.84 \mathrm{fg}$ & $15.47 \mathrm{fgh}$ & $34.67 \mathrm{a}$ \\
\hline $\mathrm{T} 13 \times \mathrm{T} 78$ & $102.81 \mathrm{a}-\mathrm{d}$ & $12.07 \mathrm{a}-\mathrm{d}$ & $28.01 \mathrm{~b}-\mathrm{g}$ & $18.81 \mathrm{c}-\mathrm{g}$ & $34.67 \mathrm{a}$ \\
\hline T64 & $80.17 \mathrm{e}-\mathrm{h}$ & $12.3 \mathrm{abc}$ & $31.25 \mathrm{a}-\mathrm{e}$ & 20.98a-f & $33.67 \mathrm{ab}$ \\
\hline T64 x T73 & $83.6 \mathrm{e}-\mathrm{h}$ & $9.67 \mathrm{de}$ & $25.04 \mathrm{efg}$ & $16.89 \mathrm{e}-\mathrm{h}$ & $34 \mathrm{ab}$ \\
\hline T64 x T78 & $74.09 \mathrm{gh}$ & $10.31 \mathrm{cde}$ & $30.89 \mathrm{a}-\mathrm{e}$ & $21.23 \mathrm{a}-\mathrm{e}$ & $34.33 \mathrm{ab}$ \\
\hline $\mathrm{T} 73$ & $106.47 \mathrm{abc}$ & $11.34 \mathrm{~b}-\mathrm{e}$ & $22.46 \mathrm{~g}$ & $13.68 \mathrm{~h}$ & $32 \mathrm{a}-\mathrm{e}$ \\
\hline $\mathrm{T} 73 \times \mathrm{T} 78$ & $90.88 c-f$ & $11.61 \mathrm{~b}-\mathrm{e}$ & $32.56 \mathrm{abc}$ & $20.23 \mathrm{~b}-\mathrm{g}$ & $30.33 \mathrm{cde}$ \\
\hline T78 & $76.26 \mathrm{fgh}$ & $11.29 \mathrm{~b}-\mathrm{e}$ & $34.21 \mathrm{ab}$ & $22.74 a-d$ & $32.67 a-e$ \\
\hline Permata F1 & $92.5 b-f$ & $11.89 \mathrm{a}-\mathrm{d}$ & $36.23 a$ & $26.35 a$ & $32.67 \mathrm{abc}$ \\
\hline Fortuna 23 & $83.41 \mathrm{e}-\mathrm{h}$ & $9.28 \mathrm{e}$ & $20.4 b-g$ & $18.78 \mathrm{c}-\mathrm{h}$ & $33.33 \mathrm{abc}$ \\
\hline New Mutiara & $88.78 d-g$ & $11.99 \mathrm{a}-\mathrm{d}$ & $35.87 \mathrm{a}$ & $22.61 \mathrm{a}-\mathrm{d}$ & $32 \mathrm{a}-\mathrm{e}$ \\
\hline
\end{tabular}

Keterangan: Angka-angka yang diikuti oleh huruf yang sama pada kolom yang sama menunjukkan tidak berbeda nyata berdasarkan uji DMRT pada taraf $5 \%$ 
vegetatif tanaman tomat memiliki nilai sangat beragam karena karakter kuantitatif banyak dikendalikan oleh banyak gen yang bersifat aditif. Hal ini menyebabkan seleksi pada karakter-karakter kuantitatif perlu dilakukan berdasarkan seleksi tidak langsung (indirect selection) (Kumar et al., 2006). Peningkatan keragaan masing-masing karakter juga memengaruhi peningkatan daya hasil tomat (Islam et al., 2010; Izge et al., 2012).

\section{KESIMPULAN}

Nilai heterosis tinggi tidak selalu diikuti oleh nilai heterobeltiosis tinggi. Genotipe yang memiliki keunggulan heterosis dan heterobeltiosis adalah T73xT78 dan T13xT64 masing-masing pada karakter diameter batang dan lebar daun. Genotipe T13 memiliki keragaan karakter tinggi tanaman lebih baik dari ketiga pembanding.

\section{UCAPAN TERIMA KASIH}

Terima kasih disampaikan kepada Direktorat Pendidikan Tinggi yang telah membiayai penelitian ini melalui Bantuan Operasional Perguruan Tinggi Negeri (BOPTN) tahun 2013 a.n. Syarifah Iis Aisyah.

\section{DAFTAR PUSTAKA}

Arif, A.B. 2010. Pendugaan parameter genetika beberapa karakter kualitatif dan kuantitatif pada tiga kelompok cabai (Capsicum annuum L.). Tesis. Sekolah Pascasarjana. Institut Pertanian Bogor.

Bar, M., N. Ori. 2014. Leaf development and morphogenesis. Development J. 141(2014):4219-4230.

Gul, R., H.U. Rahman, I.H. Khalil, S.M.A. Shah, A. Ghafoor. 2010. Heterosis for flower and fruits traits in tomato (Lycopersicon esculentum Mill.). Afric. J. Biotech. 9(27):4144-4151.Doi:10.5897/AJB09.1765.

Haghighi, M., R. Abolghasemi, J.A.T. da Silva. 2014. Low and high temperature stress affect the growth characteristics of tomato in hydroponic culture with Se and nano-Se amandement. Sci. Horti. 178(2014):231-240.

Hannan, M.M., M.A. Ahmed, M.A. Razvy, R. Karim, M. Khatun, A. Haydar, M. Hossain, U.K. Roy. 2007. Heterosis and correlation of yield and yield components in tomato (Lycopersicon esculentum Mill.). Am-Euras J. Sci. Res. 2(2):146-150.

Herison, C., Rustikawati, M. Handajaningsih. 2017. Daya gabung dan heterobeltiosis karakter pertumbuhan dan daya hasil beberapa galur backcross cabai merah toleran CMV pada kondisi terinokulasi. J. Agron. Indonesia. 45(3):292-298.
Islam, B.M.R., N.A. Ivy, M.G. Rasul, M. Zakaria. 2010. Character association and path analysis of exotic tomato (Solanum lycopersicum L.) genotypes. Bangladesh J. Plant Breed. Genet. 23(1):13-18.

Izge, A.U., Y.M. Garba, I.A. Sodangi. 2012. Correlation and path coefficient analysis of tomato (Lycopersicum esculentum L. Karst) under fruit worm (Helionthis Zea Buddie) infestation in a line $\mathrm{x}$ tester. J. Envir. Issues. and Agric. in Develop. Countries. 4(1):2430.

Jiang, K., K.L. Liberatore, S.J. Park, J.P. Alvarez, Z.B. Lippman. 2013. Tomato yield heterosis is triggered by a dosage sensitivity of the florigen pathway that finetunes shoot architecture. PloS Genet. 9(1):e1004043. Doi:10.1371/journal.pgen.1004043.

[Kementan] Kementrian Pertanian (ID). 2013. Hasil ekspor impor pertanian. http://aplikasi.deptan.go.id/eksim/ index1.asp [06 Maret 2013].

Kumar, R., N.K. Mishra, J. Singh, G.K. Rai, A. Verma, M. Rai. 2006. Studies on yield and quality traits in tomato (Solanum lycopersicon (Mill) Wettsd). Veg. Sci. 33(2):126-132.

Patwary, M.M.A., M.M. Rahman, S. Ahmad, M.A.K. Miah, H. Barua. 2013. Study of heterosis in heat tolerant tomato (Solanum lycopersicum) during summer. Bangladesh J. Agril. Res. 38(3):531-544.

Purwati, E. 2007. Perbaikan mutu tomat varietas Kaliurang. J. Agrivig. 6(3):270-275.

Savita, J.P. Singh. 2015. Heterosis for quality traits in tomato. Asian J. Plant Sci. Res. 5(7):27-32.

Shaheen, M.R., C.M. Ayyub, M. Amjad, E.A. Waraich. 2015. Morpho-physiological evaluation of tomato genotypes under high temperature stress conditions. J. Sci. Food Agric. 96:2698-2704.

Shende, V.D., T. Seth, S. Mukherje, A. Chattopadhyay. 2012. Breeding tomato (Solanum lycopersicon L.) for higher productivity and better processing qualities. Sabr. J. Breed. Gen. 44(2):302-321.

Soedomo, P.R.. 2012. Uji daya hasil lanjutan tomat hibrida di dataran tinggi Jawa Timur. J. Hort. 22(1):8-13.

De Souza, L.M., M.E.A.G.Z. Paterniani, P.C.T de Melo, A.M.T. de Melo. 2012. Diallel cross among fresh market tomato inbreeding lines. Horti. Brasil. 30:246251. 
Sumiasih, Murniati, Deviona. 2014. Keragaan karakter agronomi beberapa genotipe tomat (Lycopersicon esculentum Mill.) di dataran rendah. Jom. Faperta. 1(2):2014.

Syukur, M., S. Sujiprihati, R. Yunianti. 2012. Teknik Pemuliaan Tanaman. Penebar Swadaya. Jakarta, Indonesia.
Tamta, S., J.P. Singh. 2017. Heterosis in tomato for growth and yield traits. Intl. J. Veg. Sci. Doi:10.1080/19315 260.2017.1407857. 